\title{
Heart Failure Therapy Intensification Type
}

National Cancer Institute

\section{Source}

National Cancer Institute. Heart Failure Therapy Intensification Type. NCI Thesaurus.

Code C119234.

A classification or description of the therapeutic agent or procedure that is being escalated. 